\title{
CONFIGURAÇÕES DO INSÓLITO: O ESPAÇO LABIRÍNTICO EM "O LARGO DO MESTREVINTE" (1958), DE JOSÉ J. VEIGA
}

\author{
CONFIGURATIONS OF THE UNUSUAL: THE LABIRINTHINE \\ SPACE IN “O LARGO DO MESTREVINTE” (1958), JOSÉ J. VEIGA
}

Márcia Machado de Lima'

Resumo: É relevante o estudo da obra de José J. Veiga (1915-1999) para o campo dos estudos de literatura brasileira, dentre outros motivos, pela provocaçăo que os recursos dedicados ao espaço impóem à leitura de seus contos. Discutiremos o espaço labiríntico em "O Largo do Mestrevinte" desdobrado do conflito adultez racionalizada e o campo de experiência aberto que a criança mobiliza. O espaço cria o movimento necessário ao desenvolvimento do conflito e para que o narrador tenha que fazer as suas escolhas. Do mesmo modo, o espaço funciona para criar as condiçôes para o efeito de transgressâo próprio do fantástico no conto analisado. Veiga permitiu aproximarmo-nos da noçáo de heterotopia, e aparece, ainda, propondo questóes provocadoras, para os estudos literários, sobre o insólito.

Palavras-chave: Literatura brasileira. Espaço labiríntico. Fantástico literário. José J. Veiga.

Abstract: It is relevant to study the work of José J. Veiga (1915-1999) for the field of studies of Brazilian literature, among other reasons, for the provocation that the resources dedicated to space impose on the reading of his stories. We will discuss the labyrinthine space in "O Largo do Mestrevinte" deployed from the rationalized adult conflict and the open field of experience that the child mobilizes. Space creates the necessary movement for the development of conflict and for the narrator to make his choices. In the same way, space works to create the conditions for the effect of own transgression of the fantastic in this story. Veiga allowed us to approach the notion of heterotopia, and it also suggests provocative questions for literary studies about the unusual.

KEY WORDS: Brazilian literature. Labirinthine space. Fantastic literary. José J. Veiga.

1 Professora Adjunta da Universidade Federal de Rondônia, Doutora em Letras pela Universidade Estadual Paulista-Campus Săo José do Rio Preto. E-mail: marcia.lima@unir.br 


\section{INTRODUÇÃO}

Quando abordamos a obra de José J. Veiga, considerando a fortuna crítica e dados historiográficos sobre o conto no Brasil, encontramos um autor cuja presença é apontada no debate sobre as disposiçôes do campo literário brasileiro, especialmente pela preocupaçáo com os recursos dedicados à constituiçấo do relato breve, que valeram as mençóes feitas por críticos e historiadores. Veiga é um um escritor de personalidade, com presença frequente entre 1960 e 2000 no Suplemento Literário do Jornal O Estado de Sâo Paulo, dentre outros. A presença de Veiga no sistema literário brasileiro foi reforçada pelas citaçōes na historiografia pós-modernista (décadas de 1950-1960) do erudito historiador da literatura Afrânio Coutinho e co-autores, dentre eles Antonio Candido e Luiz Costa Lima, que também assinam o volume.

Nesta mesma linha, Bella Josef (1986) indicou o refinamento da contribuiçăo de Veiga e de Rubem Fonseca para a renovaçăo do conto no Brasil após a década de 60, no curso ministrado na Universidade Federal do Rio de Janeiro em 1971. A autora asseverou que o gênero conto atuava como renovador da literatura brasileira, o que imprimiria maior relevo às obras de Veiga e Fonseca. A posiçâo de Josef é acompanhada por Wilson Martins na muito citada coletânea Ponto de Vista, publicada na década de 70. Ao lado de Fábio Lucas e Walnice Nogueira Galvăo, durante a mesa-redonda sobre o conto, cujo texto foi publicado em 0 Livro do Seminário, em 1982, Luiz Costa Lima reiterou a necessidade de observar melhor o estilo veigueano.

As reflexōes apresentadas nesteartigo integram um estudo mais amplo, apenas iniciado, e mantêm-se atentas ao objeto principal, qual seja, a configuraçăo do insólito na obra de José J. Veiga. As escolhas para o corpus têm sido guiadas por duas chaves: há largo rol de autores, como mencionados recorrentemente por estudos recentes da série brasileira, como literatura fantástica; e supomos que o espaço possui relevância nas escolhas estéticas dos autores daquele rol.

Do ponto de vista da primeira chave de leitura, a pesquisa desenvolvida pela Profa. Dra. Maria Cristina Batalha, da Universidade Estadual do Rio de Janeiro, sobre "Os Caminhos do Fantástico: França, Brasil e Portugal" é referência para os estudos das relaçôes que entretecem o fantástico literário na literatura brasileira. A autora discute elementos historiográficos e teóricos que têm orientado a pesquisa que temos empreendido sobre a configuração do fantástico na obra de José J. Veiga. Batalha aponta para certa possibilidade ainda năo atendida plenamente: "A literatura fantástica, importante espaço de questionamento de realidades extra ficcionais pelo caminho da incerteza, tem sido pouco trabalhada entre nós [... ] apesar de o gênero nunca ter deixado de marcar sua presença na série literária brasileira" (BATALHA, 2011, [s.n]). A abordagem do gênero fantástico, entăo, na linha que aponta a autora, precisa ganhar maior número de pesquisadores. Seguindo a sua indicaçăo, enveredamos pela seara aberta que potencializa outras discussōes.

O estudioso espanhol Davi Roas (2012, p.119) insiste na possibilidade de a literatura fantástica produzir a tensâo que teria como efeito turvar o delineamento das realidades do mundo empírico. Roas indica que seria a marca central do fantástico "[...] desestabilizar esses limites que nos dăo segurança, problematizar essas convicçóes coletivas, questionar a validade dos sistemas de percepçáo da realidade comumente admitidas". Aponta para o efeito de interpelaçăo do real que tende a ser alcançado 
pelos recursos utilizados pelo autor se o insólito abarcar o mundo em sua totalidade, ou seja, se os objetos, as cenas, as características dos personagens forem identificáveis àquelas do mundo empírico:

[...] dessa maneira, o relato fantástico nos situa inicialmente dentro dos limites do mundo que conhecemos, do mundo que (digamos assim) controlamos, para em seguida rompê-lo com um fenômeno que altera a maneira natural e habitual em que ocorrem os fatos neste espaço cotidiano. (ROAS, 2012, p.122).

Para Roas, a desestabilizaçăo do mundo familiar, portanto, é o resultado esperado do processo de leitura, cujo desdobramento afetará, consequentemente, a percepçâo que o leitor faz dele. Roas indica, assim, a necessidade de instalaçăo da suspeita sobre a natureza dos pressupostos de explicaçáo do real, dos esquemas de percepçáo naturalizados; a suspeita sobre as explicaçóes do mundo, sejam elas quais forem. A suspeita năo se instala pela via realista, o que equivale a dizer, como Roas indica claramente, que o leitor năo acreditará pertencer à realidade empírica homens irmăos de sangue de dromedários (como acontece no conto "Alfredo", de Murilo Rubiáo) ou passem voando pelo céu em bolhas de sabâo imensas e etéreas (como no desfecho de "Os do Outro Lado", de José J. Veiga), mas que questionar a realidade representada possa servir para romper a naturalizaçăo das explicaçóes para os acontecimentos do mundo. Portanto, fantástico é o mundo, aquele no qual o leitor vive.

A discussăo de Roas oferece indicadores para a segunda chave de leitura que tem guiado a incursâo sobre a configuraçâo do insólito na obra de José J. Veiga. Temos que nos romances, novelas e contos, a centralidade do espaço apresentou-se notável. No premiado De Jogos e de Festas (1980), as duas novelas e o ensaio enfeixados no livro tratam das contradiçôes nas relaçôes sociais integradoras e muito fixadas, sempre permitindo que espaços pouco valorizados culturalmente funcionem lado a lado e, muitas vezes, entremeados. Como habitamos esse mundo, ou como, às vezes, rompemos, ou ainda ao contrário, como nossos corpos sucumbem a ele, parece ser o mote dos três textos.

Em outra obra, o romance Aquele Mundo de Vasabarros (1982), o título indica que haverá um lugar como centro da história. O reino inventado funciona para colocar em questăo as relaçôes políticas travadas entre os estamentos representados em Vasabarros - o mundo contido em uma única habitaçấo.Em Sombra ... temos o narrador de Sombra de Reis Barbudos (1973) a observar as interferências dos labirintos instalados em Taitara. Em A Hora dos Ruminantes (1966), crianças aparecem surfando sobre o mar de costas de touros que entupiam as ruas depois de outras invasóes, mantendo os correios e o pequeno comércio, enfim, permitindo a continuidade da vida em Mainairema. Na obra de estreia, vinte anos antes, a coletânea de contos Os Cavalinhos de Platiplanto (1959), ganhadora do Prêmio Fábio Prado, considerando-se seus títulos e sua localizaçâo no sumário, temos nova pista da inclinaçấo de Veiga à espacialidade. ${ }^{2}$

Há recorrência do espaço físico como objeto da crítica acadêmica sobre a obra de Veiga. A palavra "espaço" e outras que remetem a seu campo como "fronteira",

2 Celso Sisto, em seu artigo "Um Outro Lugar para Estar: O espaço mágico dos Meninos de J.J.Veiga", publicado na Revista Travessias, em 2009, indicava claramente a marca da espacialidade também na organizaçáo do livro Os Cavalinhos de Platiplanto. Observa que o conto "Fronteira" está localizado no meio do livro, sendo que até entâo os meninos implementam práticas de resistência, mas após, sucumbem à imposiçăo do mundo adulto e reificado. 
"ambientaçăo", "atmosfera", "arquitetura", săo recorrentes nos estudos da obra. Os pesquisadores, embora nâo indiquem acordos em bases teóricas sólidas - e năo julgamos que precisaria haver apenas uma única posiçăo fechada ou acordos consensuais -, parecem convergir para a indicaçâo do espaço como um elemento marcante na poética veigueana. Nos textos de criaçáo de José J. Veiga, palavras que remetem a "espaço" como "chăo", "buraco", "cerca", "morro", "casa", "vale", "ponte", "muro", do mesmo modo referências topológicas como "em cima de uma canastra", "em cima da árvore", "por baixo", "do outro lado" apareceriam associadas à necessidade do espaço compor as bases do conflito e fatos relevantes para o seu desenrolar. No que concerne aos títulos, "Platiplanto" é uma fazenda; "Sombra" é um fenômeno da óptica, um espaço físico no qual a luz năo penetra; "Torvelinho" é o nome de uma cidade inventada do interior de Minas Gerais; "Fronteira”, "A Ilha dos Gatos Pingados", "Usina atrás do Morro”, contos publicados em 1959, sâo também amostras de como o espaço é aspecto relevante e mobilizador da realizaçăo estética no universo veigueano. Assim, há referências em todas as etapas de sua obra, incluindo-se o último livro de contos, Objetos Turbulentos. ${ }^{3}$

Os recursos dedicados ao espaço resolvem-se em escolhas de Veiga, que os colocam na base dos conflitos, no mesmo movimento em que também ratificam o trânsito pelo insólito. Lima (2016) propóe que a inscriçáo de Veiga no rol de autores do fantástico literário seja definida năo pela mera intercorrência de cenas que năo se repetem no mundo empírico, mas pelas condiçóes as quais o autor faz valer, de transgressâo do real ou de provocador do estranhamento até níveis nos quais o real năo suporta.

Veiga cria lapsos, vazios e limiares, em última instância, porque o real tăo racionalizado e representacional começa a năo fornecer todas as explicaçôes. Neste trabalho, propomos que a configuraçáo do fantástico em Veiga atua para colocar em xeque as percepçôes sobre o real e gera o efeito fantástico como estranhamento, o que implica a subjetividade. Demonstrando suas referências foucaultianas, Fernandes discute que a

[...] construçăo da subjetividade, ou melhor, a noçăo de práticas de subjetivaçăo, sobre a memória e a história [...] afirmando que didatizados estilos de época, bem como a canonizaçáo de certos autores e obras, resultam de práticas de subjetivaçăo, refletem construçōes identitárias e săo constituídos por uma heterogeneidade discursiva na relaçăo com a história, atravessados pela memória. (FERNANDES, 2005, p.1-2). ${ }^{4}$

O contrário, entâo, questionar os processos identitários e colocar em xeque a subjetividade também fortalece a posiçâo de Fernandes, mas, principalmente, oferece a nossa leitura um terreno profícuo para justificar a relevância da pesquisa sobre as configuraçōes do fantástico em Veiga. Tornamos premissa, entâo, a condiçāo de interpelar o real como própria do fantástico literário e consideramos que é nessa seara que Veiga desdobra elementos problemáticos da condiçâo humana, fazendo-os irromper e frequentar o universo ficcional.

Estudaremos um dos traços do espaço veigueano, o labirinto, o qual se insinua no

Obras de José J. VEIGA citadas: Os Cavalinhos de Platiplanto (contos), 1958; A Hora dos Ruminantes (romance), 1966; A Estranha Máquina Extraviada (contos), 1968; Sombra de Reis Barbudos (romance), 1971; Os Pecados da Tribo (romance), 1976; De Jogos e de Festas (novelas), 1981; Aquele Mundo de Vasabarros (romance), 1982; Torvelinho Dia e Noite (romance), 1985; Objetos Turbulentos (contos), 1997. 
deslocamento do narrador e, paralelamente, verificaremos como o efeito de transgressâo do fantástico veigueano aproxima-se da noçáo de heterotopia.

\section{UM LARGO: O ESPAÇO LABIRÍNTICO}

O conflito entre a racionalidade da adultez e a experiência de perder-se dela trazida pela criança move o conto "O Largo do Mestrevinte". Como discute Lima, as obras, além de alimentarem perguntas sobre a relaçâo da literatura com a identidade, expóem esteticamente as marcas do humano. Assevera a autora que "como consequência, a literatura propóe e mantém tensâo viva: as preocupaçōes com a existência, com aquilo que compóe as representaçōes sobre si e sobre o mundo. Enfim, a literatura tem a potência de atualizá-la" (LIMA, 2017, p. 208), como a arte em outras manifestaçôes. Segundo o escritor Ricardo Azevedo, na abertura do $15^{\circ}$ Congresso de Leitura do Brasil: "É pela e na literatura que escritor e leitor realizam sonhos, alimentam fantasias, desejos e utopias, prefigurados em seus enredos, personagens e cenários, catalisadores das polaridades e ambigüidades humanas. (AZEVEDO, 2005 apud CORDEIRO, 2006, p.92)5. Mutatis mutandis, é relevante o estudo da obra de José J. Veiga para o campo dos estudos de literatura brasileira, por tudo o que expusemos, sobretudo, pela provocaçáo que os recursos dedicados ao espaço impóem à leitura de seus contos.

O espaço labiríntico participa da história de "O Largo do Mestrevinte" desdobrado no conflito adultez racionalizada e campo de experiência aberto que a criança mobiliza. O espaço cria o movimento necessário ao desenvolvimento do conflito e para que as escolhas sejam impostas ao narrador-protagonista como condiçăo sine qua non. Săo as idas e vindas do homem, por horas, em ruas que levam a becos, a quintais e a novos corredores antes năo percebidos, que expóem a arquitetura do labirinto, no conto, e o insólito das convençóes que alinhavam certo sentido de realidade.

O narrador nâo está em delírio ou em transe, muito menos perde a consciência sobre o que lhe acomete, ou mesmo, adentra o mundo onírico. Avança e retorna por caminhos que cumprem a funçáo labiríntica de mantê-lo em espaço arquitetado para que se perdesse ou, dito de outro modo, tivesse chances de deixar-se arrastar. Contudo, à força dos processos identitários e das práticas de subjetivaçăo do mundo adulto, o narrador năo se perde. A sua opçăo năo o salva do horror que se seguirá.

O narrador protagonista vive o espanto do momento exato em que procura por um lugar: o Largo do Mestrevinte. Todos o conhecem, está próximo, mas o homem náo o encontra. Enquanto narra uma coisa, revela outra. Vejamos: nâo há distanciamento que poderia dar-lhe uma possível onisciência e condiçóes de avaliar os fatos que o acometem. Apresentar-se ponderado, entăo, para o narrador, torna-se uma atitude cada vez mais impensável, comprometida pelo seu envolvimento com a sua busca e com os fatos que se desdobrarâo do encontro com um menino. Outro ponto é exatamente este: nâo se trata de um menino qualquer.

$5 \quad$ Mantida a grafia segundo o original. 
Ao final do primeiro parágrafo, temos um instigante artigo definido participando da ligaçăo realizada pela preposiçấo: "[...] Cheguei a pensar que o largo nâo existisse, mas antes de desistir resolvi perguntar ao menino" [grifo nosso]. No desenrolar da cena, a descriçâo do quarto onde o menino está sendo chamado da janela é sugestiva: "[...] mapas e gravuras nas paredes, livros em cima da mesa e uma prateleirinha de caixote com a tinta ainda cheirando fresca, e no centro do quarto uma bancadazinha de carpinteiro com serra, torno, furadeira, cepilhos, tudo arrumadinho certo" (VEIGA, 1996, p. 60). Nâo era qualquer menino. O conto assume um caminho duvidoso, de progressăo improvável, que se instala sinuoso: o leitor descobre que o enredo de "Largo do Mestrevinte" nâo é outra senăo a história do encontro do homem com o menino.

O encontro se dá em uma das idas e vindas do narrador: "Já fazia bem umas duas horas que eu andava no sol quente da tarde, subindo e descendo, indo e voltando, sem nunca chegar. (VEIGA, 1996, p.57). O espaço ficcional é elemento central na narrativa. Em primeira visada, aparecem as ruas percorridas entre as idas e vindas do narrador, que resolve obter informaçóes mais uma vez:

- Desculpe interromper, nêgo. Você sabe onde fica o Largo do Mestrevinte? Ele levantou os olhos tranquilamente, como se já estivesse esperando que eu falasse, e ficou me olhando distraído [...]. Repeti a pergunta, ele piscou como acordando, fixou os olhos em minhas máos no peitoral da janela. - Deixe eu ver suas unhas. (VEIGA, 1996, p. 58).

Depois, ampliado, o espaço revela-se organizado em becos e subidas de casas que se infestam com a turba comandada pelo menino, que passa a perseguir o narrador.

Depressa escondi as máos nos bolsos, e compreendendo que estava perdendo tempo ali virei-me para sair. [...] quando virei a esquina percebi que ele já se comunicava com outros por meio de assovios. Entrei numa rua comprida, de casinhas recuadas entre árvores, eu só via muros e cercas e partes de telhados nos váos da folhagem. Nem que eu tivesse asas năo poderia alcançar o fim da rua [...]. (VEIGA, 1996, p. 59).

Na fuga, o narrador deixa seu espanto tornar-se horror. No início do conto, entretanto, tentava animar-se: "Se as indicaçóes eram certas, o largo que eu procurava devia estar naquelas imediaçōes, no fim de uma daquelas ruazinhas de casas novas" (VEIGA, 1996, p.57). Mas precisava abrir-se, mostrar-se, mostrar as unhas: "Depressa escondi as măos nos bolsos, e compreendendo que estava perdendo tempo ali virei-me para sair. (VEIGA, 1996, p.58). O narrador, vendo-se perder tempo, nâo se submeteu aos gestos, ao rito tornado necessário pelo menino. Aos olhos do homem, rito duplamente estranho.

Do ponto de vista do espaço, "Largo" é uma escolha interessante, bastante específica, para o título do conto e para demarcar o cenário. Contudo, podemos perguntar qual a funcionalidade de um espaço que nâo se deixa acessar? No mundo empírico, "largo" é uma forma existente na cidade, interna a ela, participante dela como uma de suas peças micro a estruturá-la. Dito de outro modo, uma singularidade. Trata-se de um espaço onde desembocam várias ruas, o que o faz funcionar como centro. Inter-relacionada a outras, é uma peça que interfere e gera diferença na cidade.

Entretanto, no conto veigueano é a sua condiçâo de lapso o que faz funcionar como centro. A mençăo reiterada ao "largo" cumpre sua funcionalidade, por mobilizar a 
definiçăo vinda do mundo empírico, mas no conto é como uma ausência que cumpre seu papel na constituição do relato do narrador-protagonista.

Ainda, segundo o sentido vernáculo, "largo" é uma zona de circulaçăo e năo se presta a fomentar relaçōes. Mobiliza também o sentido de "passar ao largo", a certa distância de um ponto específico. No conto, assume sua feiçấo urbana onde há casas e moram pessoas, como informa o narrador, contudo, permanece dentro da trama da cidade da qual nâo teremos quaisquer informaçôes, vista aqui como uma entidade inalcançável pelo narrador, mas que está ali. Náo sabemos se o Largo do Mestrevinte procurado faz parte da trama inicial da cidade ou se foi constituído como fruto da urbanizaçâo. Entretanto, há a certeza de que participa dessa trama e marca sua existência.

O contexto socio-cultural aparece, novamente, com a palavra "mestrevinte". A descriçâo do quarto do menino, citada anteriormente, é exemplar. O termo sugere a noçâo de Corporaçōes de Ofício, grupos profissionais que na Idade Média começaram a se especializar, como os carpinteiros, os alfaiates, os sapateiros, morando em agrupamentos próximos às fortalezas, mas donos da matéria-prima e das ferramentas de seu ofício. Elucidativa e provocadora da nossa leitura é a discussáo do historiador Leo Huberman sobre os mestres de ofício: "A associaçáo de mercadores mantinha seus membros numa linha de conduta determinada por uma série de regulamentos [...].

Seguir à risca as regras era a condiçăo [...]; rompê-las poderia significar puniçôes de várias formas." (HUBERMAN, 1986, p.34).

Segundo o historiador, mesmo depois de passar a conviver nas oficinas, era necessário passar por provas impostas pelos donos dos instrumentos e do conhecimento. Contudo, os mestres de ofício tinham altíssima posiçăo social e autoridade. Podemos supor que as marcas no corpo - como nas unhas, por exemplo - poderiam atestar o percurso daqueles que almejassem se aproximar do mestre de ofício e, talvez, ser um deles.

"O Largo do Mestrevinte" desde o título mobiliza a consideraçăo do espaço cujo formato é definível e comandado pelos entes das cidades que avançam e se organizam, mas mostra-o como um espaço inalcançável, pois apenas cumprindo à risca as provas exigidas pelo mestre, o narrador poderia adentrá-lo. Quando o narrador escolhe esconder as unhas e náo se submeter ao menino, talvez porque sua condiçăo flagrante de adulto, por si só, deveria atestar as condiçôes de avançar, torna-se alvo da puniçấo e do horror.

\section{HETEROTOPIAS}

Na fuga e perseguiçâo, o narrador indica os sons ao redor, reveladores das pessoas. O barulho da cozinha e a roupa no varal indicadores de seu trabalho. Nâo há contato, muito menos se pode vê-las. Principalmente, o Largo do Mestrevinte mantém-se para ele como o vazio, um oco que cada vez mais toma conta da narrativa. O narrador é acometido por uma experimentaçăo: viver o confronto de sensaçóes, do terror ao espanto e à indignaçăo, sensaçóes vindas da necessidade de um homem feito esconder-se da ameaçadora turba comandada pelo menino:

Lembrei-me que os meninos daquela zona eram conhecidos pela ferocidade, náo fazia muito tempo eles tinham enforcado um afiador de facas só porque ele năo quis 
tocar Escravos de Jó com uma lâmina no esmeril. [...] Encontrei um portăo aberto e entrei. Felizmente o jardinzinho era muito maltratado, cheio de capim alto dentro e envolta dos canteiros. Agachei-me numa moita e fiquei esperando [...] eles já vinham subindo a rua montados em bicicletas, os pneus mordendo o chăo [...] Um boleava um laço, que zunia no ar por cima do muro. (VEIGA, 1996, p.59).

O narrador confronta seu estatuto de adulto - forte e sujeito de suas açôes, formado moralmente e dotado de princípios verdadeiros e universais - com a necessidade de esconder-se e com o fato de estar perdido. É exatamente nessa instabilidade que o espaço se torna desconfortável, sem referências e cheio de imagens deformadas: na visăo do narrador, o vazio.

O espaço é fantástico, é um limiar onde vive agora o narrador, do qual relata, no qual as semelhanças com aquilo que conhece săo perceptíveis, mas há forças devastadoras. Para o narrador, o vazio; entretanto nós reconhecemos a transgressăo:

\footnotetext{
O espaço no qual vivemos, pelo qual somos atraídos para fora de nós mesmos, no qual decorre precisamente a erosáo de nossa vida, de nosso tempo, de nossa história, esse espaço que nos corrói e nos sulca é também em si mesmo um espaço heterogêneo [...] Năo vivemos no vazio [...] vivemos no interior de um conjunto de relaçōes que definem posicionamentos irredutíveis uns aos outros e absolutamente impossíveis de ser sobrepostos. (FOUCAULT, 1967/1987, p.414).
}

No jardim, o inusitado, o questionamento terrível autoimputado pelo narrador e sua incômoda percepçâo de que as demais figuras estăo plenamente à vontade: o capim, o canteiro, as galinhas, a roupa no varal, a panela chiando no fogáo tudo seguindo seu funcionamento regular denunciam moradores comuns, mas ele está em sua incômoda posiçâo. Segundo Foucault, a "heterotopia tem o poder de justapor em um só lugar real vários espaços, vários posicionamentos que sâo em si próprios incompatíveis (...), posicionamentos contraditórios" (1987, p. 418), o que ajuda a entender porque para o narrador no jardim nada faz sentido, a nâo ser pensar, do alto de sua adultez, que o menino é violento e encaixá-lo nos esquemas de percepçăo racionalizados. Ele năo concebe a possibilidade de o menino ser o mestre. Os posicionamentos que o narrador identifica, mas nâo articula, estâo todos representados: o mundo do trabalho, o cotidiano, a família, o lugar da infância. O efeito transgressor próprio do fantástico literário se coloca.

Quando o narrador aplica os mesmos referenciais do mundo racionalizado para entender o que está acontecendo com ele, o espaço o coloca em xeque. Precisa fazer suas escolhas: enveredar-se pelo labirinto, atender ao solicitado pelo menino e, enfim, encontrar o Largo tăo procurado? No desconforto sem referências, a estrutura labiríntica do espaço provoca no narrador o vazio como centro.

Dito de outro modo, o vazio se instala no processamento de sentidos feito pelo narrador, no limiar em se encontra no jardim e, no mesmo movimento, se torna vetor transgressor do real. Nada faz sentido para o narrador quando aplica os mesmos referenciais do mundo racionalizado para entender o que está acontecendo com ele. Entâo, o mundo do trabalho, o cotidiano, a família, o lugar da infância săo plenamente identificados e reconhecidos como categorias de entendimento, mas năo parecem funcionar muito bem. Longe da descriçâo, a tensâo que ganha a cena passa a colocar dúvidas sobre o real porque, apesar da similitude flagrante com o mundo empírico, os elementos presentes no espaço ficcional năo oferecem as explicaçóes para os eventos. 
Transgredir o real, para a literatura fantástica, é lograr colocar em suspeita o mundo familiar do leitor e os esquemas convencionais de percepçăo do real. Aquilo que o mundo empírico é capaz de aceitar tacitamente, que se coaduna com esquemas de percepçăo do sentido prático, através dos recursos do fantástico, é colocado em questăo. Se a cada regularidade constatada o leitor consolida as suas representaçôes acerca dos objetos do mundo, sob o efeito do fantástico, segue-se a isso, a colisáo do sentido representacional com aquilo que irrompe no texto.

Ruir a linha limítrofe que oferece o lugar de segurança para continuar e compreender, mas, no mesmo movimento, problematizar os esquemas de percepçăo racionais tanto quanto os consensos sociais e culturais, este é o objetivo do fantástico, na perspectiva em que discute Roas (2014, p.97). Se compreendemos, a ideia é permitir que a realidade se mostre em toda a sua incerteza e enigmas. Deste modo, no universo da literatura fantástica, os fenômenos e situaçôes narrados tendem a escapar de qualquer explicaçăo e colocar o real sob suspeita. Consideramos que é exatamente no desfecho que o efeito transgressor logra atacar, sem defesa, o leitor.

Em "O Largo do Mestrevinte", o adulto narrador-protagonista escolhe sair do labirinto. Tudo se torna malgrado ao final porque existia uma condiçăo para que a tensăo se mantivesse. Em outras palavras, o homem năo enfrenta o labirinto, sai e retorna ao que denomina conhecimento. Permanece em um năo saber sobre o lugar que procurava, mas completo, seguro e íntegro. Definiu-se, alijado da condiçáo de encontrar o que há no centro do labirinto. O narrador permanece com a percepçâo de um vazio que explica racionalmente, ao final. Tratava-se, porém, do Largo do Mestrevinte. No desfecho, reencontrando-se, o adulto julga fechar-se para o labirinto, volta para o ordenamento - que, constata, năo foi alterado pelo tempo que passou em sua busca ${ }^{6}$ - porque para achar o Largo do Mestrevinte é necessário perder-se - perder-se das máscaras sociais. Ao narrador restou o profundo desconforto presente na ambientaçăo ao final do conto. O real representado pelas convicçóes da adultez e da racionalidade impregnadas nas escolhas do narrador foram colocadas em xeque. Para Foucault,

[...] o último traço das heterotopias é que elas têm, em relaçăo ao espaço restante, uma funçăo. Esta se desenvolve entre dois pólos extremos. Ou elas têm o papel de criar um espaço de ilusáo que denuncia como mais ilusório ainda qualquer espaço real, todos os posicionamentos no interior dos quais a vida humana é compartimentalizada. (FOUCAULT, 1967/1984, p. 420).?

“O Largo do Mestrevinte”, publicado em 1958, no Suplemento Literário do Jornal do Brasil, no Rio de Janeiro, mobiliza o espaço heterotópico (o jardim, o largo, o labirinto de justaposiçôes), de denúncia daquilo que é a racionalidade humana e das verdades que nos habitam internamente, às quais se refere Foucault.

Ressaltamos, ao final, que José J. Veiga, em bases distintas das comparaçôes com a produçấo europeia e nos distanciando da crítica que o inscreve no

\footnotetext{
6 "As heterotopias estăo ligadas, mais frequentemente, a recortes do tempo, ou seja, elas dăo para o que se poderia chamar, por pura simetria, de heterocronias; a heterotopia se póe a funcionar plenamente quando os homens se encontram em uma espécie de ruptura absoluta com seu tempo tradicional." (FOUCAULT, 1967/1984, p.418).

7 mantida grafia como no original
} 
maravilhoso latino americano, mobilizou os recursos dedicados ao espaço ficcional no registro do fantástico. Principalmente, ao lado da grande presença do fantástico na série brasileira, distingue-se, tanto pelo estilo refinado como pelo efeito de transgressâo que alcança, permitindo a apropriaçăo crítica através de referências teóricas contemporâneas. Nesse sentido, corroboramos a posiçăo de Roas de que o fantástico se atualiza.

O presente artigo pretendeu trazer algumas das questōes que nos tem feito pensar, ao menos fragmentariamente, sobre a presença do fantástico literário na literatura brasileira.

\section{REFERÊNCIAS}

BATALHA, M.C. Prefácio. In: . O Fantástico Brasileiro: contos esquecidos. Rio de Janeiro: Caetés, 2011a

BATALHA, M. C. Vertentes do Insólito na Ficçăo Brasileira: de Álvares de Azevedo a Retomada do Gótico com Flávio Carneiro. XII Congresso Internacional da ABRALIC “Centro, Centros -Ética, Estética". Universidade Federal do Paraná,[s.n.]2011b.Disponível em<https://sobreomedo.files.wordpress.com/2016/10/31102016.pdf> Acessado em 02 de fevereiro de 2016

COUTINHO, A. A Literatura no Brasil. 7.ed. Rio de Janeiro: José Olympio, 1979

FERNANDES, C.A. Forma e Efeitos de Sentido. Seminário de Estudos em Análise do Discurso (2. : 2005 : Porto Alegre, RS) Anais do II SEAD - Seminário de Estudos em Análise do Discurso [recurso eletrônico] - Porto Alegre : UFRGS , 2005. Disponível em:〈http:// www.analisedodiscurso.ufrgs.br/anaisdosead/sead2.html >acessado em dezembro de 2016

FOUCAULT,M. Outros Espaços. In. __. Ditos e Escritos.Rio de Janeiro:Jorge Zahar. 1987. v.3

HERRERA ALVAREZ; VOLOBUEF, K; WIMMER, N. Vertentes do Fantástico na Literatura. Săo Paulo:Annablume/FAPESP/UNESP-Pró-Reitoria de Pós-Graduaçăo, 2012

HUBERMAN,L. A História da Riqueza do Homem. Rio de Janeiro: Guanabara,1986

JOSEF, Bella. A Essencialidade do Homem em José J. Veiga e Rubem Fonseca. In: A

Máscara e o Enigma; a modernidade da representaçâo à transgressâo. Rio de Janeiro: Francisco Alves, 1986, p 215-227.

LIMA, L.C. O Conto na Modernidade Brasileira. In: PROENÇA JR, Domício. O Livro do Seminário. Rio de Janeiro:LR Editores, 1983, p. 174-214.

LIMA, M.M. Narradores e Clandestinidade em Contos de José J. Veiga. (Tese de Doutoramento em Letras).2016.187 p. Instituto de Biociências, Letras e Ciências Exatas (UNESP): Sâo José do Rio Preto. 2016. 
LIMA, M.M. Literatura e Identidade;consideraçóes acerca do regional. Revista de Estudos de Cultura, Literatura e Alteridade Igarapé. Universidade Federal de Rondônia. v. 5, n. 02, 2017, disponível em http://www.periodicos.unir.br/index.php/igarape/index. Acessado em 01 de agosto de 2017.

MARTINS, Wilson. Romances e contos (1960). In: Pontos de Vista. Săo Paulo: T. A. Queiróz, 1992, p 8-19.

MARTINS, Wilson. Um Realista Mágico (1968). In: Pontos de Vista. Săo Paulo: T. A. Queiróz, 1994, p 96-103.

MARTINS, Wilson. Encontros e Desencontros (1970). In: .Pontos de Vista.. Sáo Paulo: T. A. Queiróz, 1994, p 377-381.

ROAS, D. Em Torno de uma Teoria sobre o Medo e o Fantástico. Traduçáo Lara D Onofrio Longo. In: HERRERA ALVAREZ; VOLOBUEF, K; WIMMER, N. Vertentes do Fantástico na Literatura. Săo Paulo:Annablume/FAPESP/UNESP-Pró-Reitoria de Pós-Graduaçăo, 2012, p.117-142

ROAS, D. Tras los límites de lo real; una definición de lo fantástico. Madrid: Páginas de Espuma, 2011.

ROAS, D. A Ameaça do Fantástico; aproximaçōes teóricas. Traduçâo Julián Fuks. Săo Paulo: UNESP, 2014.

SISTO, C. Um Outro Lugar para Estar; o espaço mágico dos meninos de J.J.Veiga. Revista Travessias. Programa de Pós-Graduaçáo em Letras da Universidade Estadual do Oeste do Paraná. v. 03, n. 03, 2009. Disponível http://www.unioeste.br/prppg/mestrados/letras/ revistas/travessias/ed 007 Acessado em 12/01/2012.

VEIGA, J.J. O Largo do Mestrevinte. In: - A Estranha Máquina Extraviada. Rio de Janeiro: Bertrand Brasil, 1996, p.57-60.

Submetido em 18 de março de 2018 Aceito em 17 de maio de 2018 